\title{
THE USE OF SILICON TECHNOLOGY FOR AN ELECTRET MICROPHONE CONSTRUCTION
}

\author{
A.J. Sprenkels ${ }^{*}$ and P. Bergueld ${ }^{+}$ \\ ${ }^{+}$Twente University, P.O.Box 217, \\ 7500 AE, Enschede, The Netherlands \\ Twente Technology Transfer, P.O.Box 545, \\ 7500 AM, Enschede, The Netherlands
}

\section{ABSTRACT}

We present a subminiature electret microphone which has been realized in silicon using wafer processing techniques. The microphone consists of two conducting plates which form a capacitor. The lower plate (backplate) is rigid and fabricated in silicon. The upper plate (diaphragm) consists of a $6 \mu \mathrm{m}$ thick metallized Mylar foil. In the air cavity between both plates a $1 \mu \mathrm{m}$ thick silicon dioxide electret is present.

The fabrication process, such as the construction of the silicon backplate, the realization of the electret and the diaphragm attachment are described.

The microphones measure $3^{*} 3^{*} 0.3 \mathrm{~mm}$ and show a sensitivity of $1.4 \mathrm{mV} / \mu \mathrm{bar}$ and a frequency response within $\pm 1 \mathrm{~dB}$ up to $15 \mathrm{kHz}$.

\section{INTRODUCTION}

Up to now electret microphones are manufactured using conventional construction techniques. Much of the processing is performed manually, which is very labour intensive. Moreover, with these techniques the limits of miniaturization have almost been reached. The application of photolithographic processes and micro-machining for the construction of three dimensional sensor structures is well established nowadays. However, the use of these techniques for the realization of a subminiature microphone is relatively new [1]. For example the microphone in figure 1 includes a $20 \mu \mathrm{m}$ deep air-gap space, a number of holes (A) to provide the necessary connection between the air gap and the backchamber, and a diaphragm support (S). On top of the air cavity a diaphragm with upper electrode has been fixed to the backplate by means of glue via the holes $\mathrm{G}$ through the backplate.

CH2593-2/88/0000-0593\$01.00 Copyright 1988 IEEE 


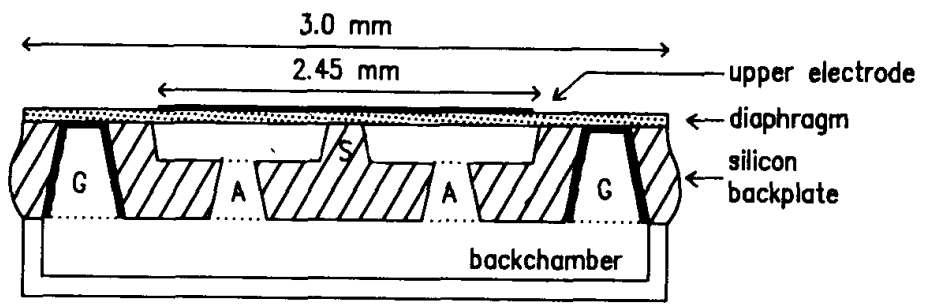

Figure 1 A schematic cross section of a silicon electret microphone.

\section{THEORY}

An electret microphone is a capacitor which is charged due to the presence of an electret between both capacitor plates. We have used silicon dioxide as the electret material.

The microphone of figure 1 may be modelled by an air gap capacitance $\mathrm{Ca}_{\mathrm{a}}$ in series with an electret capacitance $\mathrm{Cr}$, while the electret charge per unit area is represented as of as shown in figure 2. The connected amplifier $\mathrm{H}$ has an input capacitance $\mathrm{C}_{\mathrm{i}}$ and an input resistance $\mathrm{R}_{\mathrm{i}}$. It is of the utmost importance that the amplifier has a low input capacitance $\mathrm{C}_{\mathrm{i}}$ and a high input resistance $\mathbf{R}_{\mathbf{i}}$.

Due to the electret charge an electric field exists in the air gap. Sound waves acting on the diaphragm change the air-gap space Sa and thus the air-gap capacitance $C_{a}$. Since the total electret charge is constant, a variation in the air-gap capacitance $\Delta \mathrm{Ca}_{\mathrm{a}}$ is accompanied by a redistribution of the charge between the upper electrode and the backplate. This charge transfer results in a voltage variation $\Delta \mathrm{V}$ across the input resistance $R_{i}$ of the connected amplifier as schematically shown in figure 2 . In order to describe the microphone behaviour, the total sensitivity $S$, expressed in $\mathrm{V} / \mu \mathrm{bar}$ can be described as

$$
\mathrm{S}=\mathrm{Se}_{\mathrm{e}} \mathrm{m} \mathrm{H}_{\mathrm{c}},
$$

where $S_{e}$ is the electrical sensitivity, $\mathrm{H}$ is the gain of the amplifier and $\mathrm{H}_{c}$ is the capacitive attenuation by the input capacitance $\mathrm{C}_{\mathrm{i}}$ of the amplifier. $\mathrm{S}_{\mathrm{m}}$ is determined by the mechanical properties of the diaphragm and the air damping due to the shallow air gap and the backchamber. 


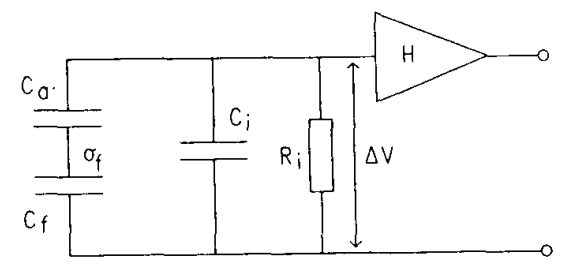

Figure 2 Schematic diagram of the electret microphone, connected to an amplifier.

For variations in the air-gap space $\mathrm{sa}$, which are fast compared to the time constant $\tau$, (which is determined by $\mathrm{R}_{\mathrm{i}}$, $\mathrm{C}_{a}, \mathrm{C} t$ and $\mathrm{C}_{\mathrm{i}}$ ) the electrical sensitivity may be approximated by [2]:

$$
S_{e}=\frac{\sigma_{f} \mathbf{s f}}{\epsilon 0(S f+\epsilon f S a)},
$$

where $\mathrm{Sf}$ is the thickness and $\epsilon$ the relative dielectric constant of the electret material. The capacitive attenuation $\mathrm{H}_{\mathrm{c}}$ is given by:

where

$$
\begin{aligned}
& H_{c}=\frac{C_{m}}{C_{m}+C_{i}} \\
& C_{m}=\frac{C_{a} C_{f}}{C_{a}+C_{f}}
\end{aligned}
$$

The mechanical sensitivity $\mathrm{S}_{\mathrm{m}}$ is determined by two restoring forces acting on the diaphragm. The first due to the mechanical properties of the diaphragm, the second due to the compression of the entire effective air volume behind the diaphragm. Assuming a zero initial tension in the diaphragm, the mechanical sensitivity of a square diaphragm with side 'a' may be approximated by:

$$
S_{m}=\frac{-1}{\left[\frac{h^{3} E\left(1+1.6(w / h)^{2}\right.}{0.138 a^{4}}\right]+\left[\frac{P_{0}}{S_{0}}\right]},
$$

where $\mathrm{h}$ is the thickness and $\mathrm{E}$ the Young modulus of the diaphragm material, $w$ is the center deflection of the 
diaphragm, $P_{0}$ is the atmospheric pressure and $\mathrm{s}_{0}$ is the effective thickness of the backchamber $[2,3]$. The total approximated sensitivity $S$ is then:

$\mathrm{S}=\frac{\sigma_{\mathrm{f}} \mathrm{sf}}{\epsilon_{0}\left(\mathrm{sf}+\epsilon_{\mathrm{fSa}}\right)} \frac{-1}{\left[\frac{\mathrm{h}^{3} \mathrm{E}\left(1+1.6(\mathrm{w} / \mathrm{h})^{2}\right.}{0.138 \mathrm{a}^{4}}\right]+\left[\frac{\mathrm{P}_{0}}{\mathrm{~S}_{0}}\right]} \mathbf{H} \frac{\mathrm{C}_{\mathrm{m}}}{\mathrm{Cm}_{\mathrm{m}}+\mathrm{Ci}_{\mathrm{i}}}$

The microphone described in this paper comprises four diaphragm supports, which are necessary to prevent the diaphragm from collapsing towards the backplate which may occur due to the electrostatic attraction. The microphone can thus be considered as to be composed of a number of small unit cells, or small microphones, operating in parallel. The dimensions of the unit cell control the sensitivity and frequency response.

Using this model a sensitivity of about $1.5 \mathrm{mV} / \mu \mathrm{bar}$ can be calculated for a microphone with the following parameters: $\mathrm{Sa}=20 \mu \mathrm{m}, \mathrm{sf}=1.1 \mu \mathrm{m}, \mathrm{Vf}_{\mathrm{f}}=325 \mathrm{~V}, \mathrm{E}=5^{*} \mathrm{E} 9 \mathrm{~N} / \mathrm{m}^{2}, \mathrm{~h}=6 \mu \mathrm{m}$, $\mathrm{a}=0.6 \mathrm{~mm}$, so $=2 \mathrm{~mm}$.

\section{MICROPHONE FABRICATION}

For the realization of the silicon backplates we start with a p-type $5-10 \Omega \mathrm{cm}(100)$-orientated silicon wafer. A $1 \mu \mathrm{m}$ thick oxide layer is used as a mask for the $\mathrm{KOH}$ solution which has been used as the anisotropic etchant. First the air cavities, with a depth of $20 \mu \mathrm{m}$, have to be etched. This is performed by etching the patterned wafer in a $\mathrm{KOH}$ solution. After subsequent oxidation, both sides of the wafer are patterned and etched simultaneously. On the reversed side of the wafer two types of holes are etched through the wafer. One type (A) end in the air-gap space and form the necessary connection between the air gap and the backchamber behind the backplate. The other type of holes $(G)$ are etched around the air cavity area, in order to be able to glue the diaphragm to the backplate (figure 1). After etching, the $\mathrm{SiO}_{2}$ the wafer is oxidized again resulting in a $1.1 \mu \mathrm{m}$ thick $\mathrm{SiO}_{2}$ layer on the entire wafer. This layer serves as the electret and is chemically treated as described in [2] and [4]. Subsequently it is charged to $315 \mathrm{~V}$ using a corona charging method. At this stage of the process the diaphragm has to be attached. This is realized by fuxation of a $6 \mu \mathrm{m}$ thick Mylar foil on top of the complete wafer. The actual attachment results from glue through the holes $(\mathrm{G})$ around the devices. Finally the wafer can be diced resulting in separate microphones. 


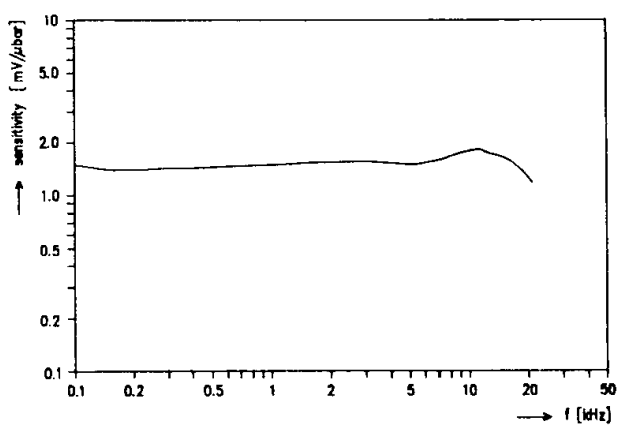

Figure 3 The measured frequency response of the prototype silicon microphone.

\section{EXPERIMENTAL}

The measured frequency response of the prototype microphones is presented in figure 3. The sensitivity is about $1.4 \mathrm{mV} / \mu \mathrm{bar}$, which is in good agreement with the calculated value. The curve in figure 4 is a typical example of one of ten microphones which have been tested. None of the ten microphones showed a discrepancy of more than $10 \%$ relative to the given example.

\section{CONCLUSIONS}

We have demonstrated that the use of photolithographic processes and anisotropic etching techniques can be succesfully employed in the realization of a subminiature electret microphone. With these techniques a large degree of reproducibility has been achieved.

It has been shown that $\mathrm{SiO}_{2}$ can be used as an excellent electret material in an electret microphone.

\section{REFERENCES}

[1] D. Hohm, "Subminiatur-Silizium-Kondensatormikrofon", Conf. proc of the DAGA '85, Stuttgart, pp.185-188.

[2] A.J. Sprenkels, A silicon subminiature electret microphone", Thesis, Twente University, 1988.

[3] G.M Sessler, ed., "Topics in applied physics", vol.33, "Electrets", Springer-Verlag, Berlin, 1980.

[4] A.J. Sprenkels, W. Olthuis and P. Bergveld, "The application of silicon dioxide as an electret material", This proceedings. 